\title{
The Impact of Biogenic Volatile Organic Compounds Emission on Photochemical Processes Occurring in the Troposphere ${ }^{* *}$
}

\section{Introduction}

Volatile organic compounds (VOCs) significantly influence the quality of the air in the ground layer of the atmosphere and play a major role in forming the climate. They are the main precursors of the tropospheric ozone as well as a source of secondary organic aerosols in the atmosphere.

VOCs get into the atmosphere both from anthropogenic and biogenic sources. Anthropogenic fraction of VOCs is associated with human industrial activities including fuel extraction and combustion processes, the refining of crude oil, metallurgy, the organic chemical industry, the production and application of solvents, the food industry, agriculture and solid waste disposal, as well as road, air and sea transport [1].

There are three main groups of anthropogenic VOCs, i.e. non-methane volatile organic compounds (NMVOCs), oxygenated volatile organic compounds and halogenated hydrocarbons (e.g. chlorofluorocarbons [CFCs], hydrofluorocarbons [HFCs]). The biosphere significantly contributes to the VOC content in the atmosphere. Living organisms inhabiting the globe through various biological processes, conditioned by a very complex system of interactions can bring a wide range of chemicals into the atmosphere, including volatile organic compounds, hereinafter referred to as BVOCs (biogenic volatile organic compounds). These compounds are emitted into the atmosphere from the surface of the Earth, including plants, soil and oceans [2-4]. They are mainly formed in the vegetative processes of some living organisms [3]. The dominant source of BVOC emission is land vegetation (trees, shrubs, grasses, ferns and mosses), as well as synantropogenic vegetation (crops, urban vegetation). This vegetation, through the process of photosynthesis, absorbs

* AGH University of Science and Technology, Faculty of Mining Surveying and Environmental Engineering, Department of Protection and Management of Environment, Krakow, Poland

** The paper has been prepared within the scope of the AGH statutory research no. 11.11.150.008 
carbon in the form of $\mathrm{CO}_{2}$, and then in favourable conditions emits approximately $1 \%$ of the absorbed carbon into the atmosphere in the form of reactive hydrocarbons [5]. The oceans, compared to land plants, are a small source of BVOCs, but they may prove significant in the emissions of certain compounds including, among others, NMVOC, oxygenated VOC, halogenated hydrocarbons or sulphurcontaining compounds such as dimethyl sulphide. Another source of BVOC emissions of lesser importance than vegetation and oceans is the soil, which may emit oxygenated VOCs.

Trees are characterized by the greatest emission of BVOCs [6]. Deciduous trees mainly emit isoprene, while conifers - terpenoids [2]. Coniferous trees also make a large contribution in the emission of oxygenated volatile organic compounds such as methanol, acetone, ethanol and acetaldehyde [7-9]. Other plants, including shrubs and grass, may be a significant source of BVOC emission as well [2].

Preliminary estimates of the global emission size of two major representatives of VOCs from biological sources, i.e. isoprene and monoterpenes, fall within the ranges of 250-450 TgC.year ${ }^{-1}$ and $128-450 \mathrm{TgC} \cdot \mathrm{year}^{-1}$. On the other hand, the share of VOC emissions from all anthropogenic sources is much smaller and is approximately $150 \mathrm{TgC} \cdot$ year $^{-1}$ [10]. Additionally, taking into account the fact that BVOCs are usually more reactive than anthropogenic VOCs, it can be concluded that, on a global scale, biogenic emissions plays a dominant role in the chemistry of the atmosphere.

While biogenic VOCs are dominant on the global scale, on the regional scale the ratio of biogenic to anthropogenic emissions of VOCs may vary significantly. The level of BVOC emission depends upon the degree of biosphere insolation, including the degree of cloudiness. Both of these factors affect the local air temperature field. The higher the temperature of the air, the greater the emission of BVOCs. Therefore, the regional emission of BVOCs determines the local chemical composition of the atmosphere, and thus the local photo-oxidative potential of the air, which has a direct impact on the possibility of the occurrence of the elevated concentrations of ozone in the air. The awareness of BVOC emission size of at the local, regional and global levels currently gains a particular importance, given that in the last 10 years, due to various pro-ecological activities, anthropogenic emission of VOCs decreased by $40 \%$ [5].

\section{The Role of BVOC in Forming Air Quality}

Photochemistry of the atmosphere is one of the integral fields of atmospheric chemistry involving reactions of molecules and atoms which occur under the influence of electromagnetic radiation.

BVOCs, due to their high reactivity, have a significant influence on the ongoing photochemical processes in the troposphere and thus determine the concentration levels of secondary air pollutants such as ozone, secondary organic aerosols or peroxyacetyl nitrate (PAN) $[2,11]$. 
Ozone is a key component of the atmosphere, which is considered to be one of the strong oxidants and greenhouse gases [12]. In addition, this compound, if occurring in the ground layer of the atmosphere, has a negative effect on human health (strongly irritating for the respiratory system), and the condition of plants (the phytotoxic effect). Tropospheric ozone is formed primarily as a result of the photochemical reactions of BVOCs and nitrogen oxides, deriving both from anthropogenic and natural sources [13]. The photolysis of ozone that occurs under the influence of ultraviolet radiation is the main source of hydroxyl radicals $\left(\mathrm{OH}^{*}\right)$ in the troposphere, though [12].

Secondary organic aerosols increase the content of solid and liquid particles in the air, worsening its sanitary condition, are conducive to the formation of clouds, reduce the transparency of the atmosphere and are a major climateforming factor. Secondary particles are formed as a result of the condensation of medium-volatile compounds formed directly in the atmosphere, in the course of chemical reactions of gaseous precursors with ozone, hydroxyl radical or nitrate radical. One of the most important precursors of the secondary aerosol are monoterpenes, volatile organic compounds emitted by plants. It is estimated that their contribution to the formation of aerosols is dominant in comparison with the hydrocarbons of anthropogenic origin. The most common monoterpene is $\alpha$-pinene, a hydrocarbon having a double bond, and which can rapidly react with atmospheric oxidants.

Peroxyacetyl nitrate is a secondary pollutant, a component of the photochemical smog. It is a stronger and more stable oxidant than ozone. Due to its durability it may be carried over long distances, where under appropriate conditions it may release $\mathrm{NO}_{2}$, conducing ozone formation.

\section{Mechanisms of BVOC Oxidation}

BVOCs can react with oxidants (such as $\mathrm{OH}^{*}$ or $\mathrm{NO}_{3}{ }^{*}$ radicals, ozone $\mathrm{O}_{3}$ or a chlorine atom) by one of the two mechanisms [2]:

1) the addition of ozone or $\mathrm{OH}^{*} / \mathrm{NO}_{3}{ }^{*}$ radicals to the double carbon bond in BVOC,

2) the abstraction of an hydrogen atom $\mathrm{H}^{*}$ from the hydrogen-carbon bond by $\mathrm{OH}^{*}$ or $\mathrm{NO}_{3}^{*}$.

The main product of BVOC oxidation is alkyl radical $\left(R^{*}\right)$, which reacts rapidly with oxygen to form an alkyl peroxy radical $\left(\mathrm{RO}_{2}{ }^{*}\right)$ [2]. The alkyl peroxy radical can then react with $\mathrm{NO}, \mathrm{NO}_{2}, \mathrm{HO}_{2}{ }^{*}$ or other alkyl peroxys $\left(\mathrm{RO}_{2}{ }^{*}\right)$. Reactions with $\mathrm{NO}_{2}$ and $\mathrm{HO}_{2}{ }^{*}$ lead to the formation of peroxy nitrates $\left(\mathrm{ROONO}_{2}\right)$ or peroxides $(\mathrm{ROOH})$. On the other hand, reactions with $\mathrm{NO}$ can contribute to the formation of $\mathrm{NO}_{2^{\prime}}$ and consequently to the formation of ozone. However, reactions of $\mathrm{HO}_{2}{ }^{*}$ lead to the creation of relatively stable products and act as a radicalsink. 
Reactions with $\mathrm{HO}_{2}{ }^{*} / \mathrm{RO}_{2}{ }^{*}$ dominate when the level of $\mathrm{NO}$ in the air is relatively low. This situation results in the removal of the radicals from circulation and inhibiting the production of ozone. The product of reaction of BVOC with peroxy radical $\mathrm{HO}_{2}{ }^{*}$ is peroxide $(\mathrm{ROOH})$, which may be deposited, photolyzed $\left(\mathrm{OH}^{*}\right.$ regeneration) or react directly with $\mathrm{OH}^{*}[2]$.

When the level of $\mathrm{NO}$ in the air is high, peroxy radical reacts with $\mathrm{NO}$ or $\mathrm{NO}_{2}$. The reaction with $\mathrm{NO}$ produces alkyl nitrate $\left(\mathrm{RONO}_{2}{ }^{*}\right)$ or alkoxy radical $\left(\mathrm{RO}^{*}\right)$. In view of the fact that alkyl nitrate is a more stable compound, it can remove NOx from the circulation. And alkoxy radical (RO*) may be isomerized or decomposed to form different products. These reactions may contribute to the formation of $\mathrm{NO}_{2^{\prime}}$ and consequently to an increase in the level of ozone in the air [2]. However, the reactions with $\mathrm{NO}_{2}$ lead to the formation of peroxy nitrates $\left(\mathrm{ROONO}_{2}\right)$, which, due to their durability, may play the role of "storage" of $\mathrm{NO}_{x}$ in the air.

\subsection{Mechanism of Monoterpene Oxidation}

The mechanism described above can be specifically presented on the example of oxidation of monoterpenes. Oxidation of monoterpenes in the atmosphere occurs as a result of the reaction with $\mathrm{OH}^{*}$ and $\mathrm{NO}_{3}{ }^{*}$ radicals, as well as of the reaction with ozone (ozonolysis). The hydroxyl radical plays a major role during the day. The monoterpenes lifetime for the reaction with $\mathrm{OH}^{*}$ (assuming the concentration of $\mathrm{OH}^{*}$ in the atmosphere at the level of $2 \times 10^{6} \mathrm{~cm}^{-3}$ estimated as the 12-hour mean value in the daytime) varies from a few minutes to several hours [14-17]. Addition of the $\mathrm{OH}^{*}$ radical to the double carbon bond is the first yet preferential step in the mechanism of the oxidation of the monoterpenes. The mechanism of oxidation based on the separation of the hydrogen atom from the monoterpene is a reaction of a lesser importance. In both cases, the alkyl radical $R^{*}$ is formed, which is then subject to the reactions described earlier.

Oxidation of monoterpenes in the atmosphere by the reaction with the radical $\mathrm{NO}_{3}{ }^{*}$ takes place only at night as $\mathrm{NO}_{3}{ }^{*}$ during the day is photodissociated or reduced by the reaction with NO. The monoterpenes lifetime for the reaction with $\mathrm{NO}_{3}{ }^{*}$ (assuming the concentration in the air at the level of $2.5 \times 10^{8} \mathrm{~cm}^{-3}$ defined as the mean value of 12 hours at night time) ranges from several minutes to several hours [14-17]. Similarly to the case with the radical $\mathrm{OH}^{*}$, also $\mathrm{NO}_{3}{ }^{*}$ radical preferentially oxidizes the monoterpene molecule by attaching to the double carbon bond, and to a lesser extent, by separating the hydrogen atom from the monoterpene molecule. As a result of this reaction, the nitroxyl or alkyl radical is created.

In the case of a reaction of monoterpene oxidation with ozone, the double carbon bond in the monoterpenes is decomposed. According to this mechanism, the oxidation takes place both in the day and night. The monoterpenes lifetime for the reaction with the ozone (assuming the concentration in the air at the level of $7 \times 10^{11} \mathrm{~cm}^{-3}$ defined as the mean value of 24 hours) ranges from a few minutes 
to a few days [14-17]. As a result of this reaction, high energy ozonide is formed, which then decomposes into compounds with a carbonyl group and the excited Criegee biradicals, which in the process of collisions with other molecules in the atmosphere are deactivated (stabilized) or unimolarly disintegrated (decomposed), or isomerized.

A unimolar decomposition pathway of Criegee biradical can take place in three different ways [16]:

1) decomposition of a particle as a result of which atomic oxygen $\mathrm{O}\left({ }^{3} \mathrm{P}\right)$ is formed and a molecule with the carbonyl group;

2) isomerization to an ester form, which in a very short period of time is decomposed;

3) intramolecular hydrogen transfer resulting from the decomposition of hydrogen peroxide formed as an intermediate product, and consequently the formation of two radicals: alkoxy radical $\left(\mathrm{RO}^{*}\right)$ and (most often) $\mathrm{OH}^{*}$ radical; the efficiency of the reaction associated with the formation of the $\mathrm{OH}^{*}$ radical in monoterpene ozonolysis depends on the type of the monoterpene. Sample values of $\mathrm{OH}^{*}$ radical production efficiency are: sabinene $-0.26, \alpha$-pinene $0.85, \beta$-pinene -0.35 , limonene -0.86 , myrcene -1.15 ; the formation of $\mathrm{OH}^{*}$ radicals by ozonolysis of monoterpenes is a more fundamental source of production of radicals at night.

Deactivated Criegee biradicals can react with $\mathrm{SO}_{2}$, aldehydes, $\mathrm{H}_{2} \mathrm{O}, \mathrm{HCOOH}$, $\mathrm{CH}_{3} \mathrm{OH}, \mathrm{CO}, \mathrm{O}_{3}, \mathrm{NO}_{2}$ and possibly $\mathrm{NO}$. In the atmosphere, due to the highest content of $\mathrm{H}_{2} \mathrm{O}$, the privileged reaction will be the one with water vapour. As a result of this reaction, hydroxyalkyl hydroperoxides will be formed, which can then decompose into carboxylic acids or aldehydes and $\mathrm{H}_{2} \mathrm{O}$ or aldehydes and $\mathrm{H}_{2} \mathrm{O}_{2}$ [16]. These products during the subsequent reactions in the gas, liquid or solid phase may lead, inter alia, to the formation of ozone and/or secondary organic aerosols.

\subsection{Mechanism of Formation of Secondary Organic Aerosols}

BVOC emission into the atmosphere also has an indirect impact on the formation of secondary aerosols, i.e. liquid or solid particles suspended in the air. While the concentration level of inorganic aerosols mainly based on sulphates and nitrates is determined on a global scale by anthropogenic sources, in the case of secondary organic aerosols, their primary emission source are biological processes. The effects of the formation of the secondary organic aerosols over the densely forested areas were already observed a relatively long time ago, e.g. by the Indians of the Cherokee tribe, who over the Great Smoky Mountains (USA) often noticed a thick blue mist, spreading over the forest-clad mountain peaks. Similar phenomena are observed in numerous places in the United States (Blue Ridge Mountains, in the states of Montana, Oregon, Idaho, Maine, Pennsylvania, Tennessee), in India (Blue Mountains), Jamaica, and on the east coast of Australia [18]. Today it is evident that 
at a time of intense solar radiation with high temperature of the air at the same time, the forests emit large quantities of unsaturated hydrocarbons into the atmosphere, such as isoprene, mono- and sesquiterpenes, which are then oxidized and whose heavy, less volatile molecules contribute to the formation of secondary organic aerosols. Also, in highly urbanized areas, a similar mist can be observed, resulting from the formation of secondary organic aerosols due to the anthropogenic VOC emission into the atmosphere.

Biogenic, but also anthropogenic secondary organic aerosols may be formed in two ways, namely by $[2,19]$ :

1) condensation of the products of oxidation in the gas phase on the existing particles in the atmosphere,

2) the nucleation or the formation of new particles (the mechanism is less important).

The ability of BVOCs to create secondary organic aerosols depends on their amount in the atmosphere, their chemical reactivity and volatility of the products of their reaction [2]. The outline of the reaction of the formation of secondary organic aerosols can be described by the example of biogenic VOCs ( $\alpha$-pinene, monoterpenes) as well as a typical representative of anthropogenic VOC - mesitylene. During the day, all of the above mentioned VOCs react very quickly with the $\mathrm{OH}^{*}$ radical to form highly reactive intermediate products. Due to the high reactivity of unsaturated alkanes of biogenic origin, similar reactions can occur between them and the ozone or $\mathrm{NO}_{3}{ }^{*}$ present in the air. The resulting intermediate products are then subjected to further reactions in the gas phase, for example with oxygen or other radical, or they form stable compounds by way of decomposition. All possible reaction pathways in the end lead to the formation of various oxidation products (with different functional groups) e.g. ketoaldehydes, ketocarboxylic acids or dicarboxylic acids. However, due to the fact that the formed reaction products have a much lower vapour pressure than the potential reactants in the atmosphere, aerosol particles are formed by way of condensation or nucleation. Some products of methylene oxidation (VOC of anthropogenic origin), for example, such as glyoxal or methylglyoxal remain in the gas phase, increasing the ozone-forming capacity of the atmosphere [18].

The above mentioned mechanisms of the formation of secondary aerosols from biogenic and anthropogenic VOCs are relatively well analyzed in terms of quality, but their quantitative description is still imperfect. We still are not able to determine precisely enough either the amount or the share of biogenic and anthropogenic emission sources in the global balance of secondary aerosols in the atmosphere. We do not know the answer to the question on the impact of secondary aerosols on climate-forming processes, either. We know, beyond any doubt, that the aerosol particles affect the sun radiation balance in the atmosphere, they are important in the formation of clouds in the troposphere, they affect the size of the droplets forming clouds and cloud albedo. 
In recent years, a common aspect for discussion associated with the organic aerosols in the atmosphere is a matter of polymerization or oligomerization of organic molecules in the solid phase [18]. The compounds identified in aerosol particles of high molecular weight and properties similar to humic substances (such as polarity, acidity, UV and fluorescence spectra) are often recognized as HULIS, humic-like substances [20]. These substances are multifunctional chemical water-soluble compounds, surface active, which results in their taking an active part in the formation of clouds.

In 2002, Myoseon Jang, Nadine M. Czoschke, Sangdon Lee and Richard M. Kamens confirmed the possibility of inclusion of organic carbonyl compounds into acid aerosol particles based on sulphuric acid [21]. Organic carbonyl compounds such as glyoxal, due to its volatility, are not able to produce aerosol particles spontaneously. Scientists listed above have found that catalytic reactions taking place in the droplet of sulphuric acid between carbonyl compounds result in an increase in their molecular weight, which in consequence leads to a reduction in the vapour pressure of the reaction products. This mechanism indicates that the formation of secondary organic aerosols is more effective in an atmosphere which is rich in $\mathrm{SO}_{2}$. This effect has been confirmed by experimental studies in aerosol chambers [21]. Further studies on the formation of secondary organic aerosols in the atmosphere have shown that the formation of multimolecular products of oxidation/decomposition of BVOCs does not need to take place in the presence of an acid aerosol at all. Research conducted in the aerosol chamber has proved that within a few hours after the decomposition of hydrocarbons it is possible to form oligomers in the solid phase [18].

Currently, there are various mechanisms describing the increase in the molecular weight of the products of BVOC decomposition (aerosol particles formation), more or less confirmed experimentally. In addition to the aforementioned mechanism of the formation of the aerosol in the acid catalysis reaction of carbonyl compounds, the mechanism of esterification or anhydride formation from the acids available in the aerosol particle should be mentioned. Recombination reaction of radicals in the gas phase is also possible, which leads to compounds of higher molecular weight. The final mechanism is the formation of multimolecular products by polymerization in aerosol droplets in the clouds.

The difficulty of making an unambiguous description of the phenomenon of forming secondary organic aerosols in the atmosphere is due to the fact of the existence of a large number of factors which determine the direction of the occurring chemical reactions in the atmosphere.

The course of the reactions depends on the qualitative and quantitative composition of trace substances in the atmosphere, on the prevailing meteorological conditions and circumstances related to the interactions between the atmosphere and the litho-, hydro- and biosphere. 


\section{Summary}

The knowledge of the impact of BVOC emissions on chemical processes occurring in the ground layer of the atmosphere plays a key role in the conscious management of air quality and influences a better understanding of the factors affecting the climate. A direct effect of BVOC emission into the air is the increase of ozone-forming potential of the ground layer of the atmosphere and the formation of secondary pollutants, which depending on the type and amount of trace substances in the atmosphere may take the form more or less stable (e.g. PAN, secondary organic aerosols). These substances, due to their physicochemical and toxicological properties, may be a greater threat to the ecosystem than the primary substances emitted to the atmosphere.

Some types of BVOC in favourable conditions are subjected to the processes of condensation, nucleation, polymerization or oligomerization often with contribution of anthropogenic pollutants (e.g. $\mathrm{SO}_{2^{\prime}} \mathrm{PM}$ ).

As a result of these processes the secondary pollutants are formed which due to their low vapour pressure can lead to formation of the aerosols substantially changing the optical parameters of the atmosphere and thereby affecting the local balance of energy exchange between the atmosphere and the surface of the Earth. All of these processes mentioned above affect the air quality and determine forming of the local climate.

\section{References}

[1] Piccot S., Watson J., Jones J.: A Global Inventory of Volatile Organic Compound Emissions From Anthropogenic Sources. Journal of Geophysical Research, vol. 97(D9), 1992, pp. 9897-9912.

[2] Koppmann R. (ed.), Carpenter L.J., Ciccioli P., Goldstein A., Hamilton J.F., Hoffmann T., Lewis A.C., Mannozzi M., O’Doherty S., Reimann S., Roberts J., Rudolph J., Shepson P., Steiner A., Warnke J., Wildt J., Williams J.: Volatile Organic Compounds in the Atmosphere, Blackwell Publishing, 2007.

[3] Kesselmeier J., Staudt M.: Biogenic volatile organic compounds (VOC): An overview on emission, physiology and ecology. Journal of Atmospheric Chemistry, vol. 33, 1999, pp. 23-88.

[4] Graedel T.E., Bates T.S., Bouwman A.F., Cunnold D., Dignon J., Fung I., Jacob D.J., Lamb B.K., Logan J.A., Marland G., Middleton P., Pacyna J.M., Placet M., Veldt C.: A compilation of inventories of emissions to the atmosphere. Global Biogeochemical Cycles, vol. 7 (1), 1993, pp. 1-26.

[5] Steinbrecher R., Koppmann R.: Bedeutung biogener Kohlenwasserstoffe. Biosphäre und Atmosphäre. Chemie in unserer Zeit, 41, 2007, pp. 286-292. 
[6] Wiedinmyer C., Guenther A., Harley P., Hewitt N., Geron C., Artaxo P., Steinbrecher R., Rasmussen R.: Global Organic Emissions from Vegetation. [in:] Granier C., Artaxo P., Reeves C. E. (ed.), Emissions of Atmospheric Trace Compounds, Springer Netherlands, 2004, pp. 115-170.

[7] Goldan P.D., Kuster W.C., Fehsenfeld F., Montzka A.: The observation of C5 alcohol emission in a North American pine forest. Geophysical Reasearch Letter, vol. 20, 1993, pp. 1039-1042.

[8] Baker B.M., Guenther A., Greenberg J., Fall R.: Canopy fluxes of 2-methyl-3buten-ol over a ponderosa pine forest by relaxed eddy accumulation: Field data and model comparison. Journal of Geophysical Research, vol. 104 (D21), 1999, pp. 26107-26144.

[9] Schade G.W., Goldstein A.H.: Fluxes of oxygenated volatile organic compounds from ponderosa pine plantation. Journal of Geophysical Research, vol. 106 (D3), 2001, pp. 3111-3123.

[10] Müller J.-F.: Geographical distribution and seasonal variation of surface emissions and deposition velocities of atmospheric trace gases. Journal of Geophysical Research: Atmospheres, vol. 97 (D4), 1992, pp. 3787-3804.

[11] Calfapietra C., Fares S., Loreto F.: Volatile organic compounds from Italian vegetation and their interaction with ozone. Environmental Pollution, vol. 157, 2009, pp. 1478-1486.

[12] Folberth G.A., Hauglustaine D.A., Lathière J., Brocheton F.: Impact of biogenic hydrocarbons on tropospheric chemistry: results from a global chemistry-climate model. Atmospheric Chemistry and Physics Discussions, vol. 5, 2005, pp. 10517-10612.

[13] Wang Q., Han Z., Wang T., Zhang R.: Impacts of biogenic emissions of VOC and $\mathrm{NO}_{x}$ on tropospheric ozone during summertime in eastern China. Science of the Total Environment, vol. 395, 2008, pp. 41-49.

[14] Atkinson R., Arey J.: Gas-phase tropospheric chemistry of biogenic volatile organic compounds: a review. Atmospheric Environment, vol. 37, suppl. 2, 2003, pp. 197-219.

[15] Calogirou A., Larsen B.R., Kotzias D.: Gas-phase terpene oxidation products: a review. Atmospheric Environment, vol. 33 (9), 1999, pp. 1423-1439.

[16] Calvert J.G., Atkinson R., Kerr J.A., Madronich S., Moortgat G.K., Wallington T.J.,Yarwood G.: The mechanisms of atmospheric oxidation of the alkenes. Oxford University Press, 2000.

[17] Tillmann R.: Bildung sekundärer organischer Aerosole durch die Oxidation von Monoterpenen: Ein massenspektrometrischer Ansatz zur Auswertung von Atmosphären-Simulationskammer Experimenten. Bergischen Universitäat Wuppertal, 2007 [Ph.D. Thesis], [online]: http://elpub.bib.uni-wuppertal. de/servlets/DerivateServlet/Derivate-892/dc0722.pdf, access: 12.01.2013.

[18] Hoffmann T., Zetzsch C., Rossi M.J.: Chemie von Aerosolen. Chemie in Unserer Zeit, vol. 41, 2007, pp. 232-246. 
[19] Kanakidou M., Seinfeld J.H., Pandis S.N., Barnes I., Dentener F.J., Facchini M.C., Van Dingenen R., Ervens B., Nenes A., Nielsen C.J., Swietlicki E., Putaud J.P., Balkanski Y., Fuzzi S., Horth J., Moortgat G.K., Winterhalter R., Myhre C.E.L., Tsigaridis K., Vignati E., Stephanou E. G., Wilson I. : Organic aerosol and global climate modelling: a review. Atmospheric Chemistry and Physics, vol. 5 (4), 2005, pp. 1053-1123.

[20] Graber E.R., Rudich Y.: Atmospheric HULIS: How humic-like are they? A comprehensive and critical review. Atmospheric Chemistry and Physics, vol. 6, 2006, pp. 729-753.

[21] Jang M.S., Czoschke N.M., Lee S. and Kamens R.M.: Heterogeneous atmospheric aerosol production by acid-catalyzed particle phase reactions. Science, vol. 298, 2002, pp. 814-817. 